\title{
Dietary patterns and risk of oral cancer: A factor analysis study of a population in Jakarta, Indonesia
}

Abstract

A matched case-control, hospital-based study of oral cancer was conducted in Jakarta population. The sample included 81 cases and 162 controls. The purpose of this study was to determine the association between dietary pattern and oral cancer in a Jakarta population using factor analysis. Dietary data were collected using food frequency questionnaire and factor analysis was performed on 15 food groups resulting in four principle factors/components being retained. The first factor "preferred" was characterized by fast food, fermented food, canned food, snacks high in fat and sugar, cooked and raw vegetables, and seafood. The second factor labeled "combination" was loaded by the intake of dairy product, red meat, white meat and fruits. The third factor labeled "chemical related was loaded by processed food and monosodium glutamate and the fourth principle component consisted of drinks and grain was labeled as "traditional". The conditional logistic regression was done using STATA 8 to obtain the odds ratio (OR) of highest tertile of each component retained from factor analysis and the ORs were then adjusted with risk habits. The consumption the highest tertile of the "preferred" pattern increased the risk of oral cancer by two-times compared to the lowest tertile of consumption [adjusted odds ratio $(\mathrm{aOR})=2.17 ; 95 \%$ confidence interval $(\mathrm{Cl})=1.05-4.50]$. The chemical related" pattern showed higher risk of about threefold $(\mathrm{aOR}=2.56 ; 95 \% \mathrm{Cl}=1.18-5.54)$, while the "traditional" pattern showed an increased of risk by twofold $(\mathrm{aOR}=2.04 ; 95 \% \mathrm{Cl}=1.01-4.41)$. In contrast, the "combination" pattern displayed protective effects in relation to oral cancer $(\mathrm{aOR}=0.50 ; 95 \% \mathrm{Cl}=$ 0.24-1.00). This finding suggests that factor analysis may be useful to determine the diet pattern of a big set of food type and establish the correlation with oral cancer.

\begin{tabular}{|c|l|}
\hline Author & $\begin{array}{l}\text { Amtha, R. ; Zain, R. ; Razak, I. A. ; Basuki, B. ; Roeslan, B. O. ; } \\
\text { Gautama, W. ; Purwanto, D. J. }\end{array}$ \\
\hline Source & Oral Oncology \\
\hline ISSN & $1368-8375$ \\
\hline DOI & $10.1016 /$ j.oraloncology.2009.01.007 \\
\hline Page & e49-e53 \\
\hline Volume & 45 \\
\hline Year & AUG 2009 \\
\hline
\end{tabular}

Keyword

Dietary patterns, Factor analysis, Indonesia, Jakarta, Oral cancer 
Please Cite As

Amtha R, Zain R, Razak IA, Basuki B, Roeslan BO, Gautama W, et al. Dietary patterns and risk of oral cancer: A factor analysis study of a population in Jakarta, Indonesia. Oral Oncology. [Article]. 2009 AUG 2009;45(8):e49-e53.

URL

- http://www.scopus.com/inward/record.url?eid=2-s2.067650444764\&partnerlD=40\&md5=02b6e3f4dd13dd83d9c97c069e332515

- http://apps.webofknowledge.com/InboundService.do?SID=Y2cPJcINhMpk4a89II a\&product $=$ WOS\&UT $=000268112800020 \&$ SrcApp $=$ EndNote\&DestFail=http\%3A $\% 2 \mathrm{~F} \% 2 \mathrm{Faccess}$.isiproducts.com\%2Fcustom images\%2Fwok5 failed auth.html \&lnit=Yes\&action=retrieve\&SrcAuth=ResearchSoft\&customersID=ResearchSoft \&mode=FullRecord

- http://www.ncbi.nlm.nih.gov/pubmed/19251469

- http://www.oraloncology.com/article/S1368-8375(09)00007-4/abstract 